\title{
BIM Business Value for Asset Owners: Key Issues and Challenges
}

\author{
Mustapha Munir, Arto Kiviniemi, Stephen W. Jones, Stephen Finnegan
}

\begin{abstract}
Purpose - There is a need to develop the understanding of asset owners concerning the constraints of Building Information Modelling (BIM) implementation, and its subsequent value realisation activities in Asset Management (AM) cannot be overstated. This is because the lifecycle cost of a built asset is three times more than construction costs and five times more than the initial investment outlays. Hence, this paper investigated and identified the key issues and challenges of realising BIM business value in AM.
\end{abstract}

Design/methodology/approach - The study adopted an explorative and deductive approach. A qualitative four-stage research design strategy was adopted using ten semistructured interviews and document analysis to collect data. These were analysed through qualitative thematic analysis.

Findings - The study identified 15 key barriers and classified them from the perspective BIM governance dimensions, namely people, process and technology. Furthermore, the study identified that more process-based challenges are experienced than people or technology. Of the identified challenges, three are people-related, eight are process-related and four are technology-related.

Practical implications - The analysed results focused on the development of the understanding of asset owners, policy-makers and researchers regarding the complex challenges that hinder BIM utilisation and value realisation in AM. The findings of this paper support progress towards enhanced BIM adoption in the Architecture, Engineering and Construction (AEC) industry by highlighting the significance of the identified challenges, their nature (people, process or technology-based) and the resultant effect on BIM value realisation during asset operations.

Originality - The original contribution of this study was the exploration and identification of the current challenges experienced by asset owners in implementing BIM during asset operations, and how these affect the derivation of BIM business value.

Paper type - Research Paper

Keywords - Building Information Modelling, Value Realisation Management, Asset Management, Challenges, Barriers. 


\subsection{INTRODUCTION}

Increasingly, technologies, such as Building Information Modelling (BIM), are used to deliver the structured and unstructured data collected for the effective management of a built asset over its lifecycle (BuildingSMART, 2018). This involves the collection of datasets, which are necessary for the operation and maintenance of built assets, such as geospatial, survey, condition monitoring, performance, and utilisation data. The use of BIM for such management and operational purposes is triggering a digital transformation in Asset Management (AM); however, it is not without its challenges. Essentially, BIM refers to a tool, technique and methodology of 'generating, storing, managing, exchanging, and sharing building information in an interoperable and reusable way' (Vanlande et al., 2008:2). Similarly, AM refers to an organised set of activities that involve the identification, acquisition, management and disposal of assets including supplementary activities, such as planning, collecting, scheduling and controlling organisational resources to make the assets efficient and effective. Furthermore, for effective AM, BIM-based data can be useful to execute business processes at the strategic, tactical and operational levels (Munir et al., 2019).

One of the central goals of the implementation of BIM in the Architecture, Engineering and Construction (AEC) industry is the delivery of building information across its lifecycle (Korpela et al., 2015). Asset owners are optimistic in deriving business value from BIM by leveraging BIM-based data to carry out management and operational tasks more efficiently. However, there have been many challenges in utilising building information models during asset operations, which have hindered asset owners from deriving value from their initial investments. The AEC industry is struggling with the transition of BIM-based deliverables from the design and construction phases to the operations and use phase. This may be due to the divergent nature between these phases in terms of the aims, objectives and scope of operations. Furthermore, the participation of asset and facility managers is limited during the initial asset development phases (Kelly et al., 2013). This creates a void because stakeholders from the design and construction phases lack the understanding to develop building information models that provide the required information to execute tasks in the operations and use phase (Jupp, 2013). Furthermore, there is a lack of interoperability amongst software systems between the design and construction and the operations and use phases (Korpela et al., 2015).

Moreover, value realisation is a crucial business process for asset owners in realising BIM business value. AEC clients have suggested that one of the major challenges of BIM adoption is the lack of knowledge and understanding of its business value (Vass and Karrbom Gustavsson, 2014). Furthermore, few studies have examined in-depth the factors and challenges that hinder the realisation of BIM business value (Love et al., 2013; Kiviniemi and Codinhoto, 2014). Thus, there is a need to develop the understanding of asset owners 
concerning the regarding of BIM implementation and the subsequent value realisation activities in AM cannot be overstated. This is because the lifecycle cost of an asset is three times more than construction costs, and five times more than the initial investment outlays. Therefore, more studies are required to provide in-depth manifestations of the challenges affecting BIM business value realisation in AM.

\subsection{LITERATURE REVIEW}

\subsection{BIM IN AM: VALUE AND OPPORTUNITIES}

Business value refers to an outcome that is considered advantageous by an organisation, whereas BIM business value pertains to positive effects in the form of benefits generated through the adoption of BIM-based processes. There is increasing interest in identifying the economic effects of BIM in the AEC industry (Vass and Karrbom Gustavsson, 2014). Plus, asset managers face significant scrutiny when providing justifications for BIM-based investments. However, the practical management of these benefits may be difficult for asset owners due to weaknesses in the value realisation strategies (Munir et al., 2018). Furthermore, the lack of value realisation in any project or activity represents an indication of failure. After all, the main purpose of value realisation is to justify, track, evaluate and create benchmarks for BIM-based investments. Therefore, it is important to highlight the challenges that hinder the ability of asset owners to derive BIM business value in AM.

BIM has promised many benefits in terms of improving the delivery and management of assets. These systems can provide the required data to establish effective AM strategies for key assets. However, there are concerns that the benefits of BIM might not be as significant as expected, and there is considerable doubt as to whether there is business value in utilising BIM in the operations and use phase (Kelly et al., 2013). This is because few studies have attempted to demonstrate BIM business value during their asset operations (Love et al., 2014). Therefore, the effects of BIM-based processes must be evaluated in order to understand the success of BIM implementation in meeting the expectations of asset owners (Vass and Karrbom Gustavsson, 2014). Albeit, Kiviniemi and Codinhoto (2014) suggest that the use of BIM will improve data structuring and access, facilitate the search for information, speed up the control process for maintenance management, and reduce reactive maintenance. In an attempt to identify BIM business value, Brous et al. (2016) reported on an owner-operator that has derived business value from BIM by streamlining their AM processes based on data-driven decision-making. This approach enhanced their proficiency to make better decisions as a result of improved business processes. Similarly, Kiviniemi and Codinhoto (2014) explored BIM benefits for asset owners and identified three key advantages: better data structuring and access; a significant reduction in time spent searching for information and performing maintenance tasks; and efficient processes in 
tracking rooms within the facility by speeding up the maintenance process. Also, Codinhoto and Kiviniemi (2014) conducted a preliminary study for an asset owner that tested BIM enabled workflows and revealed a total saving of 193 days' work and $€ 1,778$. In comparison, Becerik-Gerber et al. (2012) suggested key opportunities and application areas of BIM in asset operations, which are: locating components, facilitating real-time data access, checking maintainability, and automatically creating digital assets. Furthermore, Munir et al., (2019) highlighted the typologies of BIM business value that could be realised by an asset owner, which are: management, commerce, efficiency, industry, user and technology value. All the aforementioned studies have tried to evaluate the business value of BIM; however, there is a need for more studies that investigate the challenges and determine why few asset owners have been able to evaluate BIM business value in asset operations.

On the other hand, Love et al. (2014) highlighted the need to address management and technical challenges associated with BIM adoption and model integration during asset operations. Also, McArthur (2015) suggested that in order for asset owners to sustainably utilise building information models for asset operations, they have to: identify what data is required for asset operations; achieve interoperability; manage workflows and workloads; and manage uncertainty regarding the use of BIM. These socio-technical factors have impacted the adoption of BIM during asset operations. However, Jupp and Awad (2017) suggested a change management strategy for operational teams that supports the integration of BIM during asset operations. Moreover, leadership in owner-operator organisations is crucial to guide and inspire management and operational teams to collaborate and maximise the benefits of BIM implementation (Sanchez et al., 2016). Similarly, Love et al. (2014) suggested that asset owners will require changes to existing strategic management methods in order to successfully implement BIM and realise business value. This includes the development of BIM adoption strategies, business cases and organisational value realisation plans in order to track benefits over the asset's lifecycle and across the supply chain. Another significant factor that hinders the realisation of BIM business value by asset owners is the lack of organisational synergy between people, processes and systems (Bosch et al., 2015). Therefore, this study further explores the challenges of BIM business value from the perspectives of people, process and technology.

\subsection{DIMENSIONS OF BIM GOVERNANCE}

BIM governance is defined as the process of establishing a set of criteria for stakeholders' rights and responsibilities when managing an asset throughout its lifecycle and using an intelligent building information model (Rezgui et al., 2013). An efficient structure of BIM governance is seen as the basis for an asset owner to increase benefits and reduce risks when managing a BIM initiative (Love et al., 2014). Prodan et al., (2015) suggested governance dimensions that drive organisational initiatives, which are people, process and technology. They stated that management have a crucial role in: how employees are directed (people), 
the technique of planning and controlling activities (process), and how technical organisational resources are set-up (technology). Similarly, Bosch et al., (2015) suggested three dimensions of BIM that are vital in understanding and managing BIM-based data in the operations and use phase, which are; people, systems (technology) and process. Similarly, Alreshidi et al., (2017) proposed the following three elements of BIM governance: actors and team (people); contracts, processes and legal frameworks (process); and data management and ICT (technology). Equally, there are three imperatives for sustainable, integrated assets over whole lifecycle outcomes, which are: collaborating people, integrated processes and interoperable technologies (Owen et al., 2013). Therefore, the successful implementation and subsequent realisation of BIM benefits depends on the degree to which asset owners are able to effectively control these factors. Hence, people, process and technology offer a rationale to analyse the challenges of BIM business value realisation in AM.

- People: This refers to the human aspect responsible for the right skills, knowledge, motivation, and conditions to perform organisational activities. The human dimension establishes the leadership, human resource, governance controls and decision-making to execute BIM-based processes (Prodan et al., 2015).

- Process: This is a set of conventions that regulate and coordinate organisational activity through established business processes. The process dimension provides organisational policies, standards, protocols, workflows and defined requirements to generate products and services using BIM-based processes throughout an asset's lifecycle (Alreshidi et al., 2017).

- Technology: These are tools and techniques that facilitate communication, enhance collaboration and simplify work. Technology, as a BIM governance dimension, emanates from hardware, software and networks, as a set of IT artefacts that are utilised during data collection and analysis, and/or management in the execution of a task or service (Brous et al., 2015).

\subsection{RESEARCH METHODOLOGY}

This study aimed to investigate and identify the barriers to realising BIM business value in AM. It sought to address the following research question:

- What are the challenges of BIM business value realisation management in AM from the perspective of people, process and technology?

To answer the research question, the study adopted an exploratory and descriptive approach to investigate the challenges experienced by asset owners in realising BIM business value (Saunders et al., 2012). Exploratory research methods were utilised to identify the barriers that hinder the ability of asset owners to realise BIM business value, while descriptive methods were used to analyse the collected data and to classify the identified challenges from the perspective of people, process and technology. The study adopted a four-step methodology: Developing the research framework, collecting the primary data, analysing the data and conducting the participant validation (Figure 1). Firstly, 
the theoretical framework was developed through a literature review, and thematic analysis was utilised to establish the study themes. Secondly, ten semi-structured interviews were conducted to understand the challenges experienced by asset operations personnel in realising the business value of BIM implementation in AM. Also, documentary data was sourced during the interviews in order to further investigate the phenomenon. Documentary data collected for the study involved organisational value realisation techniques and challenges, strategic implementation guides and advisory white papers on BIM implementation. Thirdly, during the data analysis, the $\mathrm{NVivo}^{\mathrm{TM}}$ software was utilised for the transcription and coding of the semi-structured interviews and documentary data (Saunders et al., 2012). The theory driven analytical themes related to the BIM governance dimensions, and provided a structure for the data driven descriptive themes used in the analysis. Lastly, to ensure the internal consistency of the collected data, the analysed results were returned to participants to validate the accuracy of the data presented (Saunders et al., 2012).

Furthermore, the study adopted a qualitative approach to data collection and analysis. Primary data were obtained from two methods: semi-structured interviews and document analysis. The participants selected for the study were identified using purposive sampling, specifically operational construct and snowball sampling methods (Patton, 2002). These techniques were utilised because the population of BIM adopters in AM was not known, which meant that random sampling was impractical. Due to the rare cases of BIM implementation in AM, snowball sampling was partly utilised to explore the author's network and to identify potential participants. The snowball sampling technique helped in the identification of some participants that had requisite experience and were knowledgeable in the utilisation of BIM in AM. In addition, the rare cases of BIM implementation in AM led to a limitation in the availability and number of participants for this study. The criteria used to select participants were:

- Participants had an advanced level of knowledge and understanding of BIM in AM.

- Participants had experience of BIM business value realisation in AM.

- Participants were both senior and junior personnel with experience of BIM in AM.

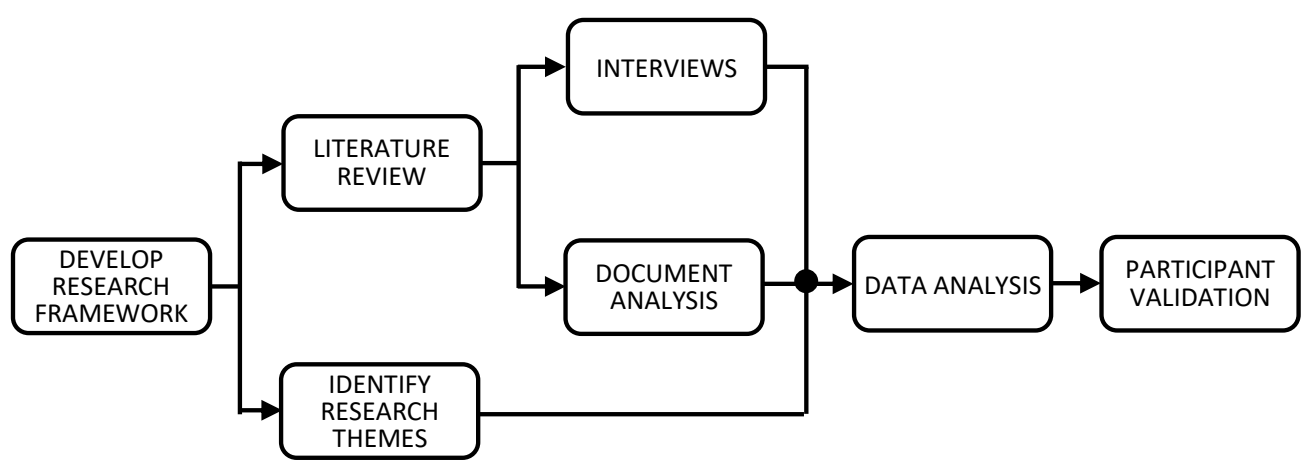

Figure 1: Research Methodology 


\subsection{RESULTS AND DISCUSSION}

This section presents the findings of the semi-structured interviews and document analysis. The NVivo $^{\mathrm{TM}}$ software aided the thematic classification of the identified challenges through the development of main and sub-thematic nodes (Figures $2, \underline{3}$ and $\underline{4}$ ).

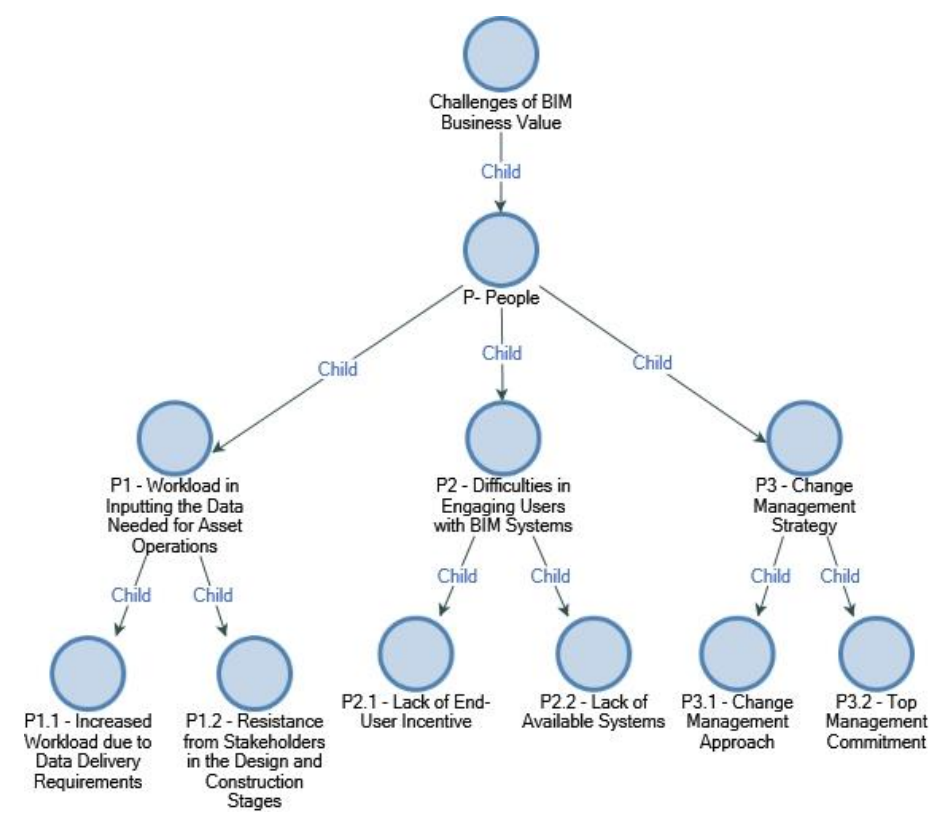

Figure 2: $\mathrm{NVivo}^{\mathrm{TM}}$ Coding Map - People Theme 


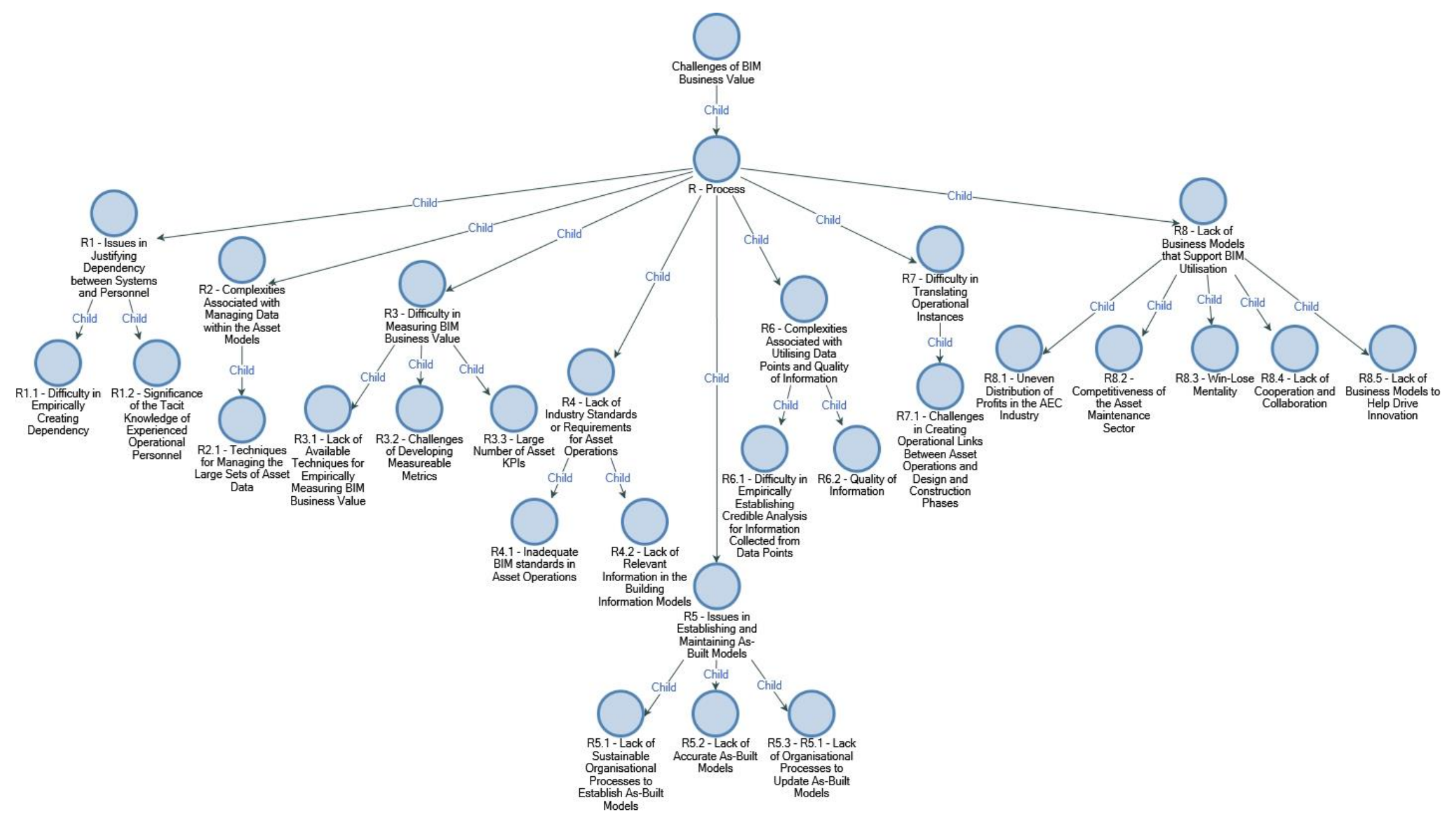

Figure 3: $\mathrm{NVivo}^{\mathrm{TM}}$ Coding Map - Process Theme 


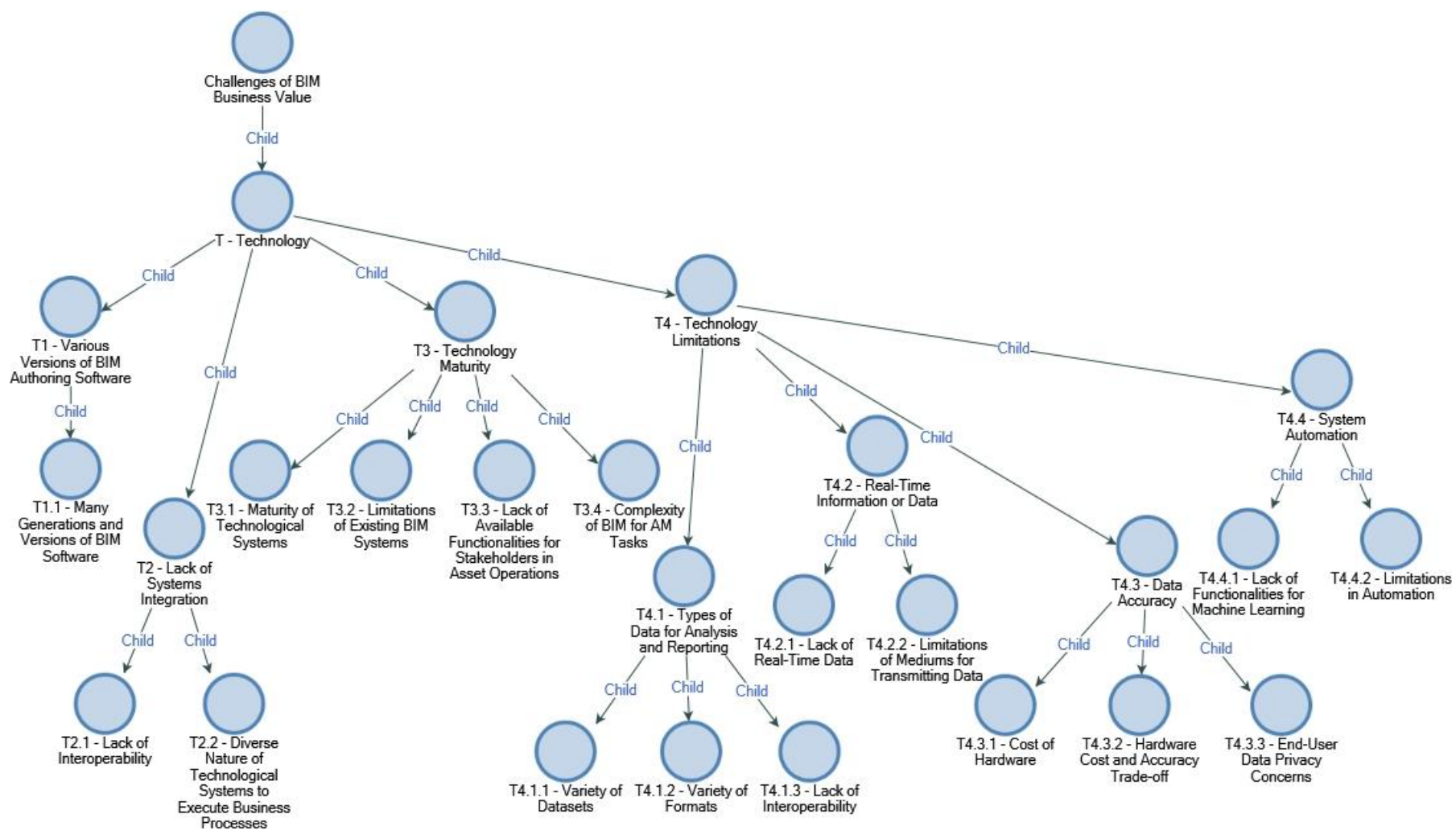

Figure 4: NVivo $^{\text {TM }}$ Coding Map - Technology Theme 
The study developed three main thematic nodes, whilst the number of sub-thematic nodes varied based on the collected and analysed data. The data analysis resulted in the classification of the challenges into three key thematic areas: people, process and technology (Figure 5). Furthermore, the study results are presented in the following sections:

\subsection{PEOPLE-RELATED CHALLENGES}

The following have been identified from the semi-structured interviews and documentary data, and classified as people-related challenges in realising business value from BIM implementation in AM.

\subsubsection{Workload in Inputting the Data Needed for Asset Operations}

A common barrier, noted by one of the participants, is the increase in workload as a result of the data delivery requirements where stakeholders are required to input nomenclature, Omniclass, family, and other standard requirements to which the BIM-based data need to conform following the design and construction stages. In some cases, the mandate to execute this activity has received some push back by stakeholders from the design and construction delivery stages, as architects, contractors, subcontractors and tradesmen have been used to the traditional methods. These cultural changes have impacted on stakeholders in the design, construction and operational phases during the development of building information models. Furthermore, without inputting data in the earlier asset development phases, stakeholders at the operational phase cannot get the required data for day-to-day tasks in a format that is consistent with AM tasks. Therefore, the lack of necessary data for operational personnel in the building information models forms a major barrier to realising BIM business value in AM. If the use of the models cannot be followed right through the built asset's lifecycle then value cannot be realised in AM. The challenge of added work in the design phase has been highlighted by the findings of Kivits and Furneaux (2013).

\subsubsection{Difficulties in Engaging Users with BIM Systems}

A major challenge is to motivate users to engage with the systems. One participant suggested that end-users see no incentive in engaging with BIM-based AM systems. Furthermore, there is a lot of potential to collect data from users that would support the asset manager to

optimise the systems and derive BIM business value. Therefore, a people-oriented approach is needed to simplify the BIM systems and to motivate the end-user to learn and gain personal benefit by uncovering end-user value and business value streams. Thus, the lack of systems available to provide services that a user would perceive as valuable forms a significant barrier in realising BIM business value in AM. Constraints related to workforce engagement have been reflected by the findings of Terreno et al. (2016). 


\subsubsection{Change Management Strategy}

Another challenge is stakeholder approach and acceptance in terms of BIM implementation in AM. The utilisation of top-down or bottom-up adoption strategies have their disadvantages in terms of the factors that each trigger, which may lead to resistance to change within an organisation. One respondent mentioned that their organisation has a bottom-up implementation approach, but highlights that this leaves a vacuum of management responsibility that leads to insufficient focus in driving the BIM initiative and communicating objectives on how to implement BIM according to the organisation's strategy. The participant further suggested that, for change to be effective, a BIM implementation strategy has to be a bullet point on the management agenda. If it is only considered from the bottom-up, then the change initiative loses strength and credibility across the organisation. Nevertheless, stakeholders at the lower and middle level management have established BIM change ambassadors who consult internally on the needs, values and benefits of BIM and communicate these to the top management. However, having similar commitment from top management remains a barrier. Thus, without synergy between all stakeholders, the BIM implementation process and successive value realisation management activities will remain obscure. Challenges related to BIM implementation strategies have been identified by Kiviniemi and Codinhoto (2014).

\subsection{PROCESS-RELATED CHALLENGES}

This section presents the process-related challenges of realising business value from BIM implementation in AM that have been identified from the semi-structured interviews and documentary data.

\subsubsection{Issues in Justifying Dependency between Systems and Personnel}

One of the main challenges is to justify the dependency between operational personnel and BIM systems during value realisation activities. A major aspect of value realisation management is the development of the business case, where justifications of proposals are made. Here, schemas are developed by using information contained in the systems in order to hypothesise and justify dependencies between the systems and operational personnel. However, one participant highlighted that they were unable to create that dependency because most of their operational personnel, including specialist contractors, knew most of the information contained in those systems by virtue of their tacit knowledge, which they had acquired through many years of experience. Thus, the dependency could only be proven with newly employed personnel. As a result, this challenge proved to be a barrier in justifying theory against practice during the BIM business value realisation activities. 


\subsubsection{Complexities Associated with Managing Data within the Asset Models}

Another challenge of BIM business value realisation management is to filter large datasets within the systems. One participant noted that there is so much data that needs to be pared down. Furthermore, the participant highlighted that the data handed over to operational personnel from the design and construction processes are useful but about $95 \%$ of the data are not required for day-to-day operations. Hence, there is a need to develop organisational processes and standards that prioritise requirements and set manageable data thresholds. Thus, without having the protocols to effectively manage BIM-based data, value cannot be realised during asset operations. Constraints related to the management of asset models have been highlighted by a number of studies (Lin et al., 2008; Brous et al., 2015; Krämer and Besenyoi, 2018).

\subsubsection{Difficulty in Evaluating BIM Business Value}

One significant challenge is to develop organisational processes that effectively track and evaluate the business value that BIM brings to the asset owner. One participant noted that they have found it difficult to isolate and appraise the benefits that BIM brings. This is because other organisational processes, personal experiences, systems and project variables also contribute to business value. However, another participant highlighted the challenge of developing measurable metrics for BIM business value. Also, explaining the difficulty in creating metrics that would allow the organisation to measure performance and subsequently evaluate BIM business value. The participant further emphasised that there are so many KPIs produced by systems but the challenge is for an organisation to relate these indicators to operational outcomes in business value terms. As a result, the inability of operational personnel to qualify BIM business value acts a significant barrier to BIM business value realisation in AM. The lack of suitable BIM business value evaluation techniques have been reflected by a number of studies (Barlish and Sullivan, 2012; Love et al., 2013; Codinhoto and Kiviniemi, 2014).

\subsubsection{Lack of Industry Standards or Requirements for Asset Operations}

A major barrier to BIM business value realisation is the lack of established BIM standards and procedures in the AEC industry. In comparison with the design and construction stages, the operations and use phase lacks standards (Becerik-Gerber et al., 2012). One participant emphasised that it is necessary for the AEC industry to develop requirements for BIM-based data to be delivered from the construction process, including standards for utilisation in the operations and use phase, in order to fully realise the business value that BIM brings. Another participant opined that personnel in the operations and use phase cannot utilise data from building models handed over from the design and construction phases because they do not contain the information that they need to perform their tasks. Further

highlighting that there is a need to develop processes and standards to make the information 
development process more collaborative so that requirements for BIM-based AM processes are captured appropriately. This is necessary because, without defined and specific standards, including the provision of relevant information, asset owners cannot effectively utilise BIM in AM tasks. As a result, value is lost from the investments made in developing building information models from the design and construction stages. The lack of industry standards for BIM-based processes in the operations and use phase has been emphasised by Becerik-Gerber et al. (2012) and Kiviniemi and Codinhoto (2014).

\subsubsection{Issues in Establishing and Maintaining As-Built Models}

A further challenge of realising BIM business value in the operations and use phase is the lack of sustainable organisational processes to establish as-built models that are accurate. One participant noted that their organisation lacks established processes to check and update as-built models. This highlights that once the as-built models are submitted by the contractors, there are no designated schedules or protocols for operational staff to check the models for compliance. Hence, in a recent audit exercise, some of the CD-ROMs containing building information models of facilities that had been submitted from the design and construction phases were found to be empty or lacking last minute changes to the built assets. Another participant identified the lack of organisational processes to update as-built models during asset operations to incorporate recent changes and/or renovations, whilst a further participant mentioned that the cost of establishing processes to maintain an up-todate building information model is a significant barrier. This highlights that the integration will only happen if the benefits brought by BIM are greater than the costs incurred in maintaining the system. Consequently, there has to be real value before the asset owner will invest in building and maintaining an up-to-date building information model. Hence, this factor represents a significant barrier because, without up-to-date building information models during the asset operations, an asset owner cannot realise BIM business value in AM. Challenges in relation to maintaining an up-to date model have been identified by a number of studies (Eastman et al., 2011; Patrick et al., 2012; Kassem et al., 2015; Krämer and Besenyoi, 2018).

\subsubsection{Complexities Associated with Utilising Data Points and Quality of Information}

Another challenge is to identify the uses and benefits of data from several building automation devices that collect data from built assets. One participant indicated that some of the data from the building information models proved to be incomplete, and, in some cases, the datasets lacked complete historical asset maintenance activities. As a result, the building models lacked important meta-information, such as real envelopes, project start dates, project end dates, maintenance data, and so forth. This made it difficult for the asset manager to properly track and document changes, and derive BIM business value. 
Complexities associated with information quality have been highlighted by the findings of Lin et al. (2008) and Zadeh et al. (2017).

\subsubsection{Difficulty in Translating Operational Instances}

An additional process-based challenge experienced by asset operations personnel is the ability to translate classifications, such as object families, to instances in the operations and use phase. One participant asserted that the classification systems represent many unique attributes where a single class may have hundreds of different values. This is due to differences in the structure of data use in the design phase, which differs significantly to those in the operations and use phase. Hence, this presents a huge challenge for asset managers when translating classifications to operational instances. Hence, without developing BIM-based processes to bridge these gaps, it will continue to be difficult to realise the value of BIM in asset operations. The challenge of object recognition and identification in relation to operational functionality has been reflected by the findings of Volk et al. (2014).

\subsubsection{Lack of Business Models that Support BIM Utilisation}

One of the problems of the AEC industry that acts as a barrier for BIM implementation and its subsequent value realisation is the current operational business models. One participant noted that the profit margins are unfairly distributed and the businesses at the bottom of the chain lack the motivation to improve and innovate. This is because the building operations and maintenance sector is very competitive, price levels are low, and personnel work under pressure, which leads to a high level of customer complaints and low customer satisfaction. This is further exacerbated by the Win-Lose mentality that predominates in the AEC industry (Latham, 1994; Egan, 2008). Therefore, the higher a business is in the value chain, the better it earns and vice-versa. As a result, businesses at the low end of the value chain are restricted to the lowest-cost business models, which stifles innovation in the building maintenance sector and subsequently hinders the effective adoption of BIM in asset operations. Furthermore, there are no shared common goals between the investor, constructor, and enduser, which leads to a breakage in the flow of BIM value business over the lifecycle of a built asset. This leads to the situation where the end-user or client is typically dissatisfied.

Another participant highlighted the lack of business models to help drive innovation in asset operations. These business models are associated with smart cities, platform economies, smart-grid solutions and/or on-demand maintenance solutions that utilise building automation data for revolutionised maintenance techniques. Thus, the development of new business models to utilise the multiple data points in relation to its 3D-geometry per building may drive BIM business value in AM. Hence, without the existence of business models that have the potential to drive business value for the asset owner by improving building performance through pre-testing, prefabrication or self-diagnostics, the realisation of BIM 
business value by the asset owner will remain a challenge. The need for innovative business models has been reflected by the findings of Kivits and Furneaux (2013).

\subsection{TECHNOLOGY-RELATED CHALLENGES}

The following have been identified from the semi-structured interviews and documentary data, and have been classified as technology-related challenges in realising the business value of BIM implementation in AM.

\subsubsection{Various Versions of BIM Authoring Software}

One of the challenges of utilising BIM in the operations and use phase is the existence of different versions of BIM authoring software. One participant noted that this presents a bottleneck when the asset owner wants to make changes to the building information models 10,20 , or 30 years later as a result of changes or renovations to the facility. The participant further highlighted that authoring software typically have many generations and they have realised that they are not able to make changes to some of the models because they were authored in previous versions. In some cases, the models have had to be redeveloped from scratch. Therefore, technological barriers such as these make it difficult for asset owners to utilise the building information models, which in turn hinders their use and any resultant BIM business value.

\subsubsection{Lack of Systems Integration}

The lack of systems integration is a significant technology-based challenge that hinders the realisation of BIM business value in AM. One participant stated that, in some cases, operational personnel would have to manually update three or more different systems, such as computer maintenance management systems, energy management systems and property management systems and the like. This results from the diverse nature of business processes in AM and the existence of little or no integration between these systems. Thus, the lack of synergy presents a challenge for asset owners in realising BIM business value in AM. The lack of systems integration across asset lifecycle phases has been reflected by a number of studies (Becerik-Gerber et al., 2012; Codinhoto and Kiviniemi, 2014; Pärn et al., 2017).

\subsubsection{Technology Maturity}

Another challenge of realising BIM business value is the maturities and limitations of existing technologies. One participant expressed that BIM is largely seen as a design tool and not generally suited for personnel in the operations and use phase. AM and Facility Management (FM) personnel view it as a complicated tool for use in their daily tasks. Furthermore, they highlighted the need for further development of BIM tools because they have been developed for the design phase and are overly complicated for the in-use phase. Another participant 
highlighted that there are challenges to the available functionalities of technological solutions in the global market for AM and FM business processes. In addition, there is a lack of advancement of tools for this phase compared with those for the design and construction phases. Thus, without the availability of more tools and functionalities that would simplify AM tasks, operational personnel would not be able to derive value from BIM. Challenges in relation to undeveloped and complex technologies for the operations and use phase have been highlighted by a number of studies (Becerik-Gerber et al., 2012; Codinhoto and Kiviniemi, 2014; Volk et al., 2014; Fregonese et al., 2015).

\subsubsection{Technology Limitations}

One of the technological challenges in realising BIM business value is represented by the current limitations of building automation systems. These challenges are reported as different types:

1. Types of data for analysis and reporting: One of the challenges of utilising building automation data is the variety of datasets and formats. The systems lack the capacity to connect to many devices and integrate the data generated into the database or asset information model. This leads to the challenge of setting organisational processes to interpret the data from building automation systems.

2. Real-time information or data: Another major challenge is the generation of asset data in real-time. For instance, if there are unusual indoor conditions in the facility, the ideal situation would be for the asset manager to know immediately and not the day after. This constraint results from the limitations of the building automation systems. Bluetooth lacks the capability to report every second, whilst radio frequency may only be able to send ten messages per day, and traditional systems are not connected to the Internet, meaning that data are manually reported once a day.

3. Data accuracy: This is another limitation of the current building automation systems used to collect asset data. It presents a bottleneck for the asset owner because accurate sensors are expensive and as a result, there is a trade-off between accuracy and cost. Also, privacy is a concern in situations where employees are made to wear electronic tags. In this case, data analytics have to make use of non-sensitive imperfect signals, such as the number of times the lighting systems are triggered or the number of times that doors are opened. Accuracy, cost and privacy are limitations to adopting and utilising appropriate signals to transmit useful data from building automation systems.

4. System automation: Another limitation is system automation. Although data can be generated automatically from assets, a second level of automation is required to automatically detect faults. The development of reliable rulesets for machine learning and prediction is a current challenge in realising value from building automation 
systems. Hence, further development is required for the rulesets in order to filter and alert for important deviations within the asset database.

The aforementioned challenges lead to a significant barrier in the use of building automation and BIM systems to derive value for the asset owner. Complexities associated with building automation systems and limitations have been highlighted by the findings of Domingues et al. (2016) and Aste et al. (2017).

\begin{tabular}{|c|c|c|c|c|}
\hline S/No & CHALLENGES & PEOPLE & PROCESS & TECHNOLOGY \\
\hline 1 & Workload in Inputting the Data Needed for Asset & P1 & & \\
\hline 2 & Difficulties in Engaging Users with BIM Systems & P2 & & \\
\hline 3 & Change Management Strategy & P3 & & \\
\hline & & & & \\
\hline 4 & $\begin{array}{l}\text { Issues in Justifying Dependency between Systems and } \\
\text { Personnel }\end{array}$ & & R1 & \\
\hline 5 & $\begin{array}{l}\text { Complexities Associated with Managing Data within the } \\
\text { Asset Models }\end{array}$ & & R2 & \\
\hline 6 & Difficulty in Measuring BIM Business Value & & R3 & \\
\hline 7 & $\begin{array}{l}\text { Lack of Industry Standards or Requirements for Asset } \\
\text { Operations }\end{array}$ & & R4 & \\
\hline 8 & Issues in Establishing and Maintaining As-Built Models & & R5 & \\
\hline 9 & $\begin{array}{l}\text { Complexities Associated with Utilising Data Points and } \\
\text { Quality of Information }\end{array}$ & & R6 & \\
\hline 10 & Difficulty in Translating Operational Instances & & R7 & \\
\hline 11 & Lack of Business Models that Support BIM Utilisation & & R8 & \\
\hline 12 & Various Versions of BIM Authoring Software & & & $\mathrm{T} 1$ \\
\hline 13 & Lack of Systems Integration & & & $\mathrm{T} 2$ \\
\hline 14 & Technology Maturity & & & T3 \\
\hline 15 & Technology Limitations & & & $\mathrm{T} 4$ \\
\hline
\end{tabular}

Figure 5: Key issues and challenges in realising BIM business value in AM

\subsection{DISCUSSION}

Asset managers face several barriers in managing and measuring BIM business value. Therefore, there is a need to develop the understanding of asset owners on the nature of challenges experienced in BIM implementation in AM that hinder the realisation of business value. An increased understanding of these challenges is necessary to comprehend how they impact BIM adoption and subsequent business value realisation activities in the AEC industry. Through the BIM governance dimensions, the challenges were explored and deduced under three categories: people, process and technology. Thus, the study addresses 
the research question by identifying key challenges that act as barriers to BIM business value realisation and management in AM.

In terms of people, the findings reveal that the challenges experienced by asset owners in adopting BIM-based AM are strategic and perceptive in nature. Most significantly, the acceptance, support and contribution by stakeholders at all levels are necessary to enable BIM-based processes and their subsequent value realisation. Considerable attention should be paid to people-related factors that focus on the development of strategies for the effective implementation of BIM-based processes that integrate stakeholders at the strategic, tactical and operational management levels. In terms of process, the results indicate that asset owners are still struggling to cope with the changes brought by BIM-based processes in AM. Critically, efficient BIM-based business processes have to be in place to enable effective business value realisation. Particular attention should be paid by asset owners to the process-related challenges that include a lack of efficient processes to manage data, standards and protocols, value measurement strategies, and techniques to support business models in AEC industry. Addressing this challenge is critical in order for asset owners to satisfactorily derive business value from BIM. In terms of technology, the findings suggest a negative perception amongst asset managers concerning the technologies available and considering the lack of existing functionality for BIM-based AM processes. Most importantly, technological solutions provide an enabling virtual environment that facilitates BIM-based processes, which in turn drives value for the asset owner. Technological challenges relating to systems integration and technological limitations require special consideration to further develop systems that are tailored to BIM-based AM processes in order to enable asset owners to efficiently utilise these systems and derive business value from BIM.

Furthermore, previous studies have not sufficiently examined the challenges experienced in realising BIM business value during asset operations (Jupp, 2013; Kelly et al., 2013; Love et al., 2013; Kiviniemi and Codinhoto, 2014; Korpela et al., 2015; Parlikad and Jafari, 2016; Robert et al., 2018; Dixit et al., 2019). Thus, an original contribution of this study is the exploration of these challenges and the identification of new potential challenges, particularly from the perspective of the asset manager and in relation to value realisation. Whilst some of the challenges identified in this study may have some similarities with those from the design and construction phases, the specific focus given to AM and BIM business value realisation provides further opportunity to develop more domain specific solutions, as highlighted in this study.

\subsection{CONCLUSION}

The purpose of the study was to investigate and identify the barriers in realising BIM business value for AM. The literature review provided evidence of a consensus concerning the value and potential of BIM in AM. Furthermore, it provided the basis for exploring the 
key issues and challenges from the BIM governance dimensions. Overall, the study highlighted the current challenges experienced by asset managers when implementing BIM during asset operations and how these affect the derivation of BIM business value from the perspectives of people, process and technology. In relation to practical implications, the analysed results focused on the development of the understanding of asset owners, policymakers and researchers regarding the complex challenges that hinder BIM utilisation and value realisation in AM. Also, the findings of this paper support progress towards enhanced BIM adoption in the Architecture, Engineering and Construction (AEC) industry by highlighting the significance of the identified challenges, their nature (people, process or technology-based) and the resultant effect on BIM value realisation during asset operations.

The findings of this study led to three main conclusions. Firstly, there is value in realising BIM, although the challenges identified need to be overcome by the AEC industry in order to realise BIM business value. Secondly, the study identifies 15 key challenges that affect BIM business value realisation in AM. Lastly, there are more process-based challenges than those for people or technology. Of the 15 identified challenges, three are people-related, eight are technology-related and four are process-related. This indicates that the efforts made by asset owners are insufficient in relation to the adaptation of operational business processes for integrated BIM-based AM. 


\section{REFERENCES}

Alreshidi, E., Mourshed, M. and Rezgui, Y. (2017) 'Factors for effective BIM governance', Journal of Building Engineering, vol. 10, pp. 89-101, Available: ISSN 2352-7102.

Aste, N., Manfren, M. and Marenzi, G. (2017) 'Building automation and control systems and performance optimization: a framework for analysis', Renewable and Sustainable Energy Reviews, vol. 75, pp. 313-330, Available: 1364-0321.

Barlish, K. and Sullivan, K. (2012) 'How to measure the benefits of BIM - a case study approach', Automation in Construction, vol. 24, pp. 149-159.

Becerik-Gerber, B., Jazizadeh, F., Li, N. and Calis, G. (2012) 'Application areas and data requirements for BIM enabled facilities management', Journal of construction engineering and management, vol. 138, no. 3, pp. 431-442.

Bosch, A., Volker, L. and Koutamanis, A. (2015) 'BIM in the operations stage: bottlenecks and implications for owners', Built Environment Project and Asset Management, vol. 5, no. 3, pp. 331-343.

Brous, P., Herder, P. and Janssen, M. (2015) 'Towards modelling data infrastructures in the asset management domain', Procedia Computer Science , vol. 61, no. 1, pp. 274-280.

Brous, P., Herder, P. and Janssen, M. (2016) 'Governing asset management data infrastructures', Procedia Computer Science 9, vol. 95, no. 1, pp. 303-310.

BuildingSMART (2018) Infrastructure Asset Managers BIM Requirements: Version 1: Delivering the information 'Asset Managers' need and can trust using openBIM, BuildingSMART International, Available: https://www.buildingsmart.org/wpcontent/uploads/2018/01/18-01-09-AM-TR1010.pdf [23 Mar 2019].

Codinhoto, R. and Kiviniemi, A. (2014) 'BIM for FM: a case support for business life cycle', 11th IFIP International Conference on Product Lifecycle Management, 7-9 July 2014, Yokohama, Japan, 63-74.

Dixit, M.K., Venkatraj, V., Ostadalimakhmalbaf, M., Pariafsai, F. and Lavy, S. (2019) 'Integration of facility management and building information modeling (BIM): a review of key issues and challenges', Facilities, vol. 1, no. 1, pp. 1-31.

Domingues, P., Carreira, P., Vieira, R. and Kastner, W. (2016) 'Building automation systems: Concepts and technology review', Computer Standards \& Interfaces, vol. 42, pp. 1-12, Available: 0920-5489.

Eastman, C., Teicholz, P., Sacks, R. and Liston, K. (2011) BIM Handbook: a guide to Building Information Modeling for owners, managers, designers, engineers and contractors, $2^{\text {nd }}$ edition, Hoboken: John Wiley \& Sons, Inc. 
Fregonese, L., Achille, C., Adami, A., Fassi, F., A, S. and Taffurelli, L. (2015) 'BIM: An integrated model for planned and preventive maintenance of architectural heritage', Digital Heritage, 28 September - 2 October 2015, Granada, Spain, 77-80.

Jupp, J. (2013) 'Incomplete BIM implementation: exploring challenges and the role of product lifecycle management functions', 10th Product Lifecycle Management for Society (PLM), 6-10 July 2013, Nantes, France, 630-640.

Jupp, J. and Awad, R. (2017) 'A change management perspective on BIM-FM implementation', AUBEA 2017: Australasian Universities Building Education Association Conference 2017, 3-5 July, EPiC Series in Education Science, vol. 1, Melbourne, Australia, 361370.

Kassem, M., Kelly, G., Dawood, N., Serginson, M. and Lockley, S. (2015) 'BIM in facilities management applications: a case study of a large university complex', Built Environment Project and Asset Management, vol. 5, no. 3, pp. 261-277.

Kelly, G., Serginson, M., Lockley, S., Dawood, N. and Kassem, M. (2013) 'BIM for facility management: a review and a case study investigating the value and challenges', Proceedings of the 13th International Conference on Construction Applications of Virtual Reality, 30-31 October 2013, London, UK, 191-199.

Kiviniemi, A. and Codinhoto, R. (2014) 'Challenges in the implementation of BIM for FM- case Manchester town hall complex', Proceedings of the 2014 International Conference on Computing in Civil and Building Engineering, 23-25 June 2014, Orlando, Florida, USA, 665-672.

Kivits, R.A. and Furneaux, C. (2013) 'BIM: enabling sustainability and asset management through knowledge management', The Scientific World Journal, vol. 2013, Article ID 983721.

Korpela, J., Miettinen, R., Salmikivi, T. and Ihalainen, J. (2015) 'The challenges and potentials of utilizing building information modelling in facility management: the case of the Center for Properties and Facilities of the University of Helsinki', Construction Management and Economics, vol. 33, April, pp. 3-17.

Krämer, M. and Besenyoi, Z. (2018) 'Towards digitalization of building operations', IOP Conference Series: Materials Science and Engineering.

Lin, S., Gao, J. and Koronios, A. (2008) 'A data quality framework for engineering asset management', Australian Journal of Mechanical Engineering, vol. 5, no. 2, pp. 209219, Available: ISSN: 1448-4846.

Love, P.E.D., Matthews, J., Simpson, I., Hill, A. and Olatunji, O.A. (2014) 'A benefits realization management building information modeling framework for asset owners', Automation in Construction, vol. 37, no. 1, pp. 1-10. 
Love, P.E.D., Simpson, I., Hill, A. and Standing, C. (2013) 'From justification to evaluation: Building information modeling for asset owners', Automation in Construction Volume, vol. 35, no. 1, pp. 208-216.

McArthur, J.J. (2015) 'A building information management (BIM) framework and supporting case study for existing building operations, maintenance and sustainability', Procedia Engineering, vol. 118, pp. 1104-1111, Available: ISSN 1877-7058.

Munir, M., Kiviniemi, A. and Jones, S.W. (2018) 'Building Information Modelling (BIM) value realisation framework for asset owners', eWork and eBusiness in Architecture, Engineering and Construction: Proceedings of the 11th European Conference on Product and Process Modelling (ECPPM 2018), 12-14 September, 2018, Copenhagen, Denmark, 313-320.

Munir, M., Kiviniemi, A., Jones, S.W. and Finnegan, S. (2019) 'BIM business value through effective asset information management', Facilities, vol. ahead-of-print, no. aheadof-print, https://doi.org/10.1108/F-03-2019-0036

Owen, R.L., Amor, R., Dickinson, J., Prins, M. and Kiviniemi, A. (2013) Research roadmap report : integrated design and delivery solutions (IDDS), Rotterdam: International Council for Research and Innovation in Building and Construction (CIB).

Parlikad, A.K. and Jafari, M. (2016) 'Challenges in infrastructure asset management', International Federation of Automatic Control (IFAC), vol. 49, no. 28, pp. 185-190.

Pärn, E.A., Edwards, D.J. and Sing, M.C.P. (2017) 'The building information modelling trajectory in facilities management: a review', Automation in Construction, vol. 75, pp. 45-55, Available: ISSN 0926-5805.

Patrick, R., Munir, M. and Jeffrey, H. (2012) 'Building Information Modeling (BIM), utilized during the design and construction phase of a project has the potential to create a valuable asset in its own right ('BIMASSET') at Handover that in turn enhances the value of the development', Proceedings of the 12th International Conference for Enhanced Building Operations (ICEBO) Conference, 23 - 26 October, 2012, Manchester, UK.

Patton, M.Q. (2002) Qualitative evaluation and research methods, $3^{\text {rd }}$ edition, Thousand Oaks: Sage Publications, Inc.

Prodan, M., Prodan, A. and Purcarea, A.A. (2015) 'Three new dimensions to people, process, technology improvement model', in Rocha, A., Correia, A.M., Costanzo, S. and Reis, L.P. (ed.) New contributions in information systems and technologies advances in intelligent systems and computing, vol 353, London: Springer Link Publishing.

Rezgui, Y., Beach, T. and Rana, O. (2013) 'A governance approach for bim management across lifecycle and supply chains using mixed-modes of information delivery', Journal of Civil Engineering and Management, vol. 19, no. 2, pp. 239-258. 
Robert, C.J., Pärn, E.A., Edwards, D.J. and Aigbavboa, C. (2018) 'Digitalising asset management: concomitant benefits and persistent challenges', International Journal of Building Pathology and Adaptation, vol. 36, no. 2, pp. 152-173.

Sanchez, X.A., Mohamed, S. and Hampson, D.K. (2016) 'BIM benefits realisation management', in Sanchez, X.A., Hampson, D.K. and Vaux, S. (ed.) Delivering value with BIM: a whole-of-life approach, $1^{\text {st }}$ edition, London: Routledge.

Saunders, M., Lewis, P. and Thornhill, A. (2016) Research methods for business students, $7^{\text {th }}$ edition, Harlow: Pearsons.

Terreno, S., Anumba, C.J. and Dubler, C. (2016) 'BIM-Based management of building operations', Construction Research Congress 2016, May 31-June 2, 2016, San Juan, Puerto Rico.

Vanlande, R., Nicolle, C. and Cruz, C. (2008) 'IFC and Buildings Lifecycle Management', Automation in Construction, vol. 18, no. 1, pp. 70-78.

Vass, S. and Karrbom Gustavsson, T. (2014) 'The perceived business value of BIM', Proceedings at the 10th European Conference on Product and Process Modelling, ECPPM 2014, 17 September 2014 through 19 September 2014, Vienna, 21-25.

Volk, R., Stengel, J. and Schultmann, F. (2014) 'Building information modeling (BIM) for existing buildings - literature review and future needs', Automation in Construction, vol. 38, March, pp. 109-127.

Zadeh, P.A., Wang, G., Cavka, H.B., Staub-French, S. and Pottinger, R. (2017) 'Information Quality Assessment for Facility Management', Advanced Engineering Informatics, vol. 33, pp. 181-205, Available: ISSN 1474-0346. 